\title{
SCREENING OF METAL HYDRIDE PAIRS FOR CLOSED THERMAL ENERGY STORAGE SYSTEMS
}

\author{
Aswin N. ${ }^{\mathrm{a}}$, Pradip Dutta ${ }^{\mathrm{a}, \mathrm{b}^{*}}$ and S. Srinivasa Murthy ${ }^{\mathrm{b}}$ \\ ${ }^{\mathrm{a}}$ Department of Mechanical Engineering, Indian Institute of Science, Bangalore, India \\ ${ }^{\mathrm{b}}$ Interdisciplinary Centre for Energy Research, Indian Institute of Science, Bangalore, India \\ *Corresponding author: E-Mail - pradip@ mecheng.iisc.ernet.in
}

\begin{abstract}
Thermal energy storage systems based on metal/hydrides usually are closed systems composed of two beds of metal/alloy - one meant for energy storage and the other for hydrogen storage. It can be shown that a feasible operating cycle for such a system using a pair of metals/alloys operating between specified temperature values can be ensured if the equilibrium hydrogen intake characteristics satisfy certain criteria. In addition, application of first law of thermodynamics to an idealized operating cycle can provide the upper bounds of selected performance indices, namely volumetric energy storage density, energy storage efficiency and peak discharge temperature. This is demonstrated for a representative system composed of $\mathrm{LaNi}_{4.7} \mathrm{Al}_{0.3}-\mathrm{LaNi}_{5}$ operating between $353 \mathrm{~K}$ and $303 \mathrm{~K}$ which gave values of about $56 \mathrm{kWhm}^{-3}$ for volumetric storage density, about $85 \%$ for energy storage efficiency and $343 \mathrm{~K}$ for peak discharge temperature. A system level heat and mass transfer study considering the reaction kinetics, hydrogen flow between the beds and heat exchanger models is presented which gave second level estimates of about $40 \mathrm{kWhm}^{-3}$ for volumetric energy storage density, $73 \%$ for energy storage efficiency and $334 \mathrm{~K}$ for peak temperature for the representative system. The results from such studies lead to identifying metal/alloy pairs which can be shortlisted for detailed studies.
\end{abstract}

Keywords: Thermal energy storage, Chemisorption, Metal hydride, Energy storage density

\section{NOMENCLATURE}
$a \quad$ Area of flow $\left(\mathrm{m}^{2}\right)$
$A, B \quad$ Parameters in Eqn. (34)
$c \quad$ Specific heat capacity $\left(\mathrm{Jkg}^{-1} \mathrm{~K}^{-1}\right)$
C Heat capacity rate $\left(\mathrm{WK}^{-1}\right)$
$h \quad$ Specific enthalpy $\left(\mathrm{Jkg}^{-1}\right)$
$H \quad$ Enthalpy of reacting species per unit mass of $\mathrm{H}_{2}\left(\mathrm{Jkg}^{-1}\right)$
I Additional heat capacity of bed $\left(\mathrm{JK}^{-1}\right)$
$K \quad$ Overall heat conductance $\left(\mathrm{WK}^{-1}\right)$ 


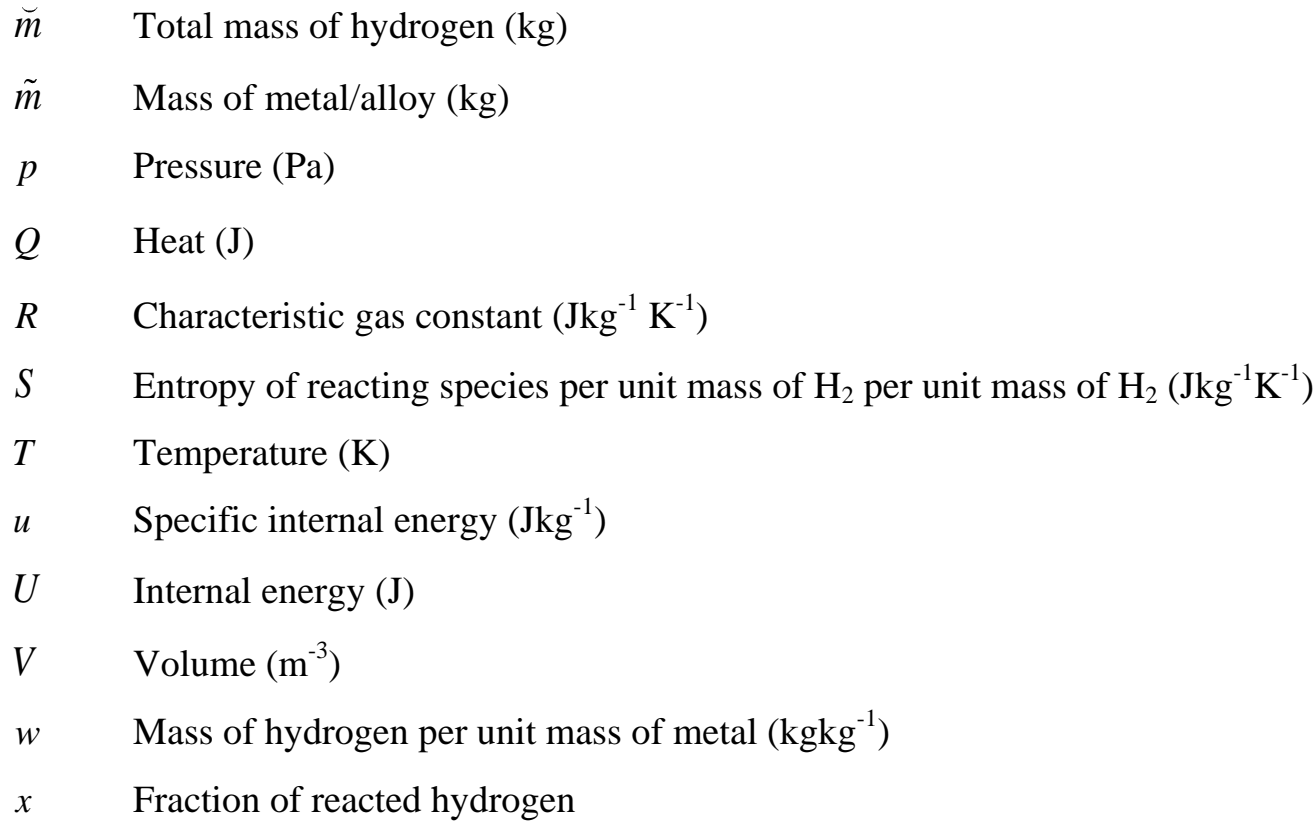

Greek letters

$\beta \quad$ Hysteresis factor in Eqn. (34)

ò Porosity

$\eta \quad$ Energy storage efficiency

$\phi, \tilde{\phi} \quad$ Slope factor in Eqn. (34)

$\rho \quad$ Density $\left(\mathrm{kgm}^{-3}\right)$

$\sigma \quad$ Rate constant in reaction kinetics $\left(\mathrm{s}^{-1}\right)$

$\zeta \quad$ Volumetric energy storage density $\left(\mathrm{Jm}^{-3}\right)$

$\xi \quad$ Bed volume ratio

\section{Superscripts}

$\ominus \quad$ Standard state

a Metal/alloy

e Energy storage bed

g Gas

h Hydrogen storage bed

m Metal/alloy hydride

$\mathrm{r} \quad$ Reacted hydrogen

v Void

Subscripts

d Discharge

D Hydride decomposition

e Equilibrium 


$\begin{array}{ll}\text { f } & \text { Heat transfer fluid } \\ \text { F } & \text { Hydride formation } \\ \text { h } & \text { High } \\ \text { H } & \text { Hydrogen } \\ \text { i } & \text { Inlet } \\ \text { l } & \text { Low } \\ \text { m } & \text { Maximum } \\ \text { o } & \text { Outlet } \\ \text { p } & \text { Plateau }\end{array}$

\section{INTRODUCTION}

A thermal energy storage based on metal/alloy hydride falls under the category of thermochemical energy storage in which available heat is used to carry out a reversible endothermic reaction usually involving decomposition of a species (charging). The products of decomposition are stored separately. When the demand for heat arises, the stored products are allowed to react in order to liberate the required heat (discharging) while regenerating the initial species. The most attractive feature of such thermal energy storage systems is the possibility of storage at ambient temperature which would enable long term energy storage without thermal losses- an obvious advantage over sensible and latent heat storage systems and one of the prominent reasons for sustained research interest in thermochemical energy storage systems. In addition, the chemical reactions promise high energy storage density due to their large heat of reaction. The reactions identified for this include ammonia dissociation, formation of metal hydrides, oxides, hydroxides and carbonates. Even though ammonia based heat storage systems can yield higher energy storage densities compared to hydrogen based ones, they have the drawback of toxicity, corrosion and poor heat and mass transfer. For a metal/alloy hydride based thermal energy storage system, the endothermic reaction involved is the hydride formation reaction. Chemisorption is the primary process associated with hydride formation and is accompanied by liberation of heat. The products of hydride decomposition are namely, unreacted metal/alloy and gaseous hydrogen. Hydride forming metals/alloys possess a wide range of operating temperature and have properties that can be tailored to a large extent by alloying different components.

Studies on metal hydrides have been mainly aimed at their application to hydrogen storage [1-3]. Thermal energy storage using the chemisorption property of metal hydrides has generally been studied along with heat pump and cooling applications. One of the well-studied systems in that category was HYCSOS (Hydride Conversion and StOrage System) which used $\mathrm{LaNi}_{5}$ and $\mathrm{MmNi}_{5}$ in multiple two bed systems operating in tandem $[4,5]$. Another study for heat storage along with hydrogen in automobiles suggested titanium for low temperature and magnesium for high temperature 
energy storage systems [6]. A nickel doped magnesium based system as a part of a small scale solar thermal power station was reported by Wierse et al. [7]. There is a renewed interest in exploring the possibilities of metal hydride based thermal energy storage systems, especially for small scale Concentrated Solar Power (CSP) which need compact, high intensity thermal storage systems.

One of the simplest and widely accepted configurations of metal/alloy hydride based thermal energy storage systems, is a closed system with two metal/alloy beds- one meant for energy storage and the other for hydrogen storage, without active pumping of hydrogen between the beds. Among the considerable number of pairs of metals/alloys for such a system, it is possible to identify which have the compatible characteristics to operate a feasible cycle under constrained temperature limits (the heat source temperature and the ambient temperature). In addition, the estimate for energy storage density presented commonly, is the product of the full hydrogen capacity of the material (gravimetric or volumetric) and the heat of hydride formation reaction. For closed systems involving two metal/alloy beds, the application of first law of thermodynamics to a feasible operating cycle with idealized processes can provide better estimates of the upper bounds of performance indices after considering the operating cycle and details of the hydrogen storage bed. In addition, a system level heat and mass transfer analysis considering the reaction kinetics and mass transfer between the beds can improve the estimates further. Eventually both the above methods would allow a stringent screening process for the material pairs falling in the same space of operating conditions and reduce effort put into detailed studies by narrowing down onto to a smaller number of promising, materials. The work presented here, details the aforementioned analyses and presents its application on a $\mathrm{LaNi}_{4.7} \mathrm{Al}_{0.3}-\mathrm{LaNi}_{5}$ system.

\section{CHARACTERISTICS OF HYDROGEN - METAL/ALLOY SYSTEM}

A system containing hydrogen and metal/alloy has hydrogen gas existing in the voids of porous metal /alloy. The state of hydrogen gas in the system can be fully described by specifying the pressure and temperature of the gas. Provided the quantity metal/alloy in the system is known, the composition of solid phase (metal/alloy along with its hydride) can be described by specifying the fraction of reacted hydrogen. The fraction of reacted hydrogen $(x)$ represents the instantaneous mass of hydrogen in the form of hydride as a fraction of the maximum mass of hydrogen that the metal/alloy in the system can react with ( $w_{\mathrm{m}}^{\mathrm{r}}$ which is a property of the selected metal/alloy). The total mass of hydrogen in the system can be given as,

$$
\breve{m}=\tilde{m} w_{\mathrm{m}}^{\mathrm{r}} x+\rho^{\mathrm{g}} V^{\mathrm{v}}
$$

where the void volume,

$$
V^{\mathrm{v}}=\grave{\mathrm{o}} V
$$


For systems in equilibrium, the fraction of reacted hydrogen can be expressed as a function of the pressure and temperature of coexisting hydrogen gas. Therefore equilibrium states are conventionally described by the $p-x-T$ characteristics of the system and depicted as isotherms in the $p-x$ plane. The isotherms for many materials exhibit hysteresis in the hydride formation and decomposition curve. There are mathematical forms of $p-x-T$ characteristics which accommodate this behaviour.

An isotherm in the $p-x$ plane of hydrogen-metal/alloy systems in equilibrium usually exhibits a plateau, where the fraction of reacted hydrogen varies drastically at an almost constant value of pressure called the plateau pressure. The plateau pressure can be related to the temperature associated with the isotherm by the van't Hoff relation using the enthalpy and entropy changes during hydride formation reaction.

$$
\ln \left(\frac{p_{\mathrm{p}}}{p^{!}}\right)=\frac{-\Delta S}{R}+\frac{\Delta H}{R T}
$$

For systems not in equilibrium, the hydride formation/decomposition reaction would be in progress and the rate of reaction, expressed as the rate of change of fraction of reacted hydrogen, is expressed as a function of instantaneous pressure, temperature and fraction of reacted hydrogen in the system. This forms the mathematical model for reaction kinetics in the system.

$$
\dot{x}=\frac{d x}{d t}=k(p, x, T)
$$

\section{SYSTEM DESCRIPTION}

A basic thermal energy storage system is a closed system as shown in Figure 1 consisting of two interconnected metal/alloy beds with hydrogen flowing back and forth during the charging and discharging processes. The beds usually contain different metals/alloys. One of the two beds functions as the energy storage bed. It receives heat from the high temperature source to decompose the metal hydride while charging the system. The other bed, namely the hydrogen storage bed, is kept close to the ambient temperature throughout and acts as a storage device for consuming and generating hydrogen respectively during charging and discharging. The energy storage bed after decomposition of metal hydride is disconnected from the hydrogen storage bed and cooled to ambient temperature for long term storage purposes. It is connected to the hydrogen storage bed to liberate heat by exothermic hydride formation reaction during discharging process. The flow of hydrogen between the beds is entirely due to difference in pressure between the beds.

\section{SELECTION OF METALS/ALLOYS}

The operation of the closed two bed thermal energy storage system starts from a dead state in equilibrium with the ambient. The beds stay connected to allow transfer of hydrogen and therefore 
contain hydrogen gas at the same pressure $\left(p_{1}\right)$. The metal/alloy for each bed is to be chosen such that the energy storage bed has a larger fraction of metal hydride than the hydrogen storage bed in the dead state (at ambient temperature). The charging process involves heating of the energy storage bed by the heat source to a higher temperature. Hydrogen is transferred to the hydrogen storage bed due to the rising gas pressure in the energy storage bed owing to the liberation of hydrogen from metal. At the end of the heating of energy storage bed during the charging, the two beds would again have equal pressures ( $p_{\mathrm{h}}$ higher than dead state value) with energy storage bed at high temperature. At this point, it is desired to have a lower fraction of reacted hydrogen in the energy storage bed and a higher value in hydrogen storage bed. This criteria is depicted in Figure 2.

It can be observed from Figure 2 that, satisfying this criteria needs the isotherms of the materials at specified temperatures to be stacked in a certain order which will impose some restrictions on the compatible characteristic curves and therefore the materials. If the isotherms of the materials exhibit a plateau in their isotherms, it can be observed that the following condition can ensure the compatibility in a large number of cases.

$$
p_{\mathrm{p}}^{\mathrm{e}}\left(T_{1}\right)<p_{\mathrm{p}}^{\mathrm{h}}\left(T_{1}\right)<p_{\mathrm{p}}^{\mathrm{e}}\left(T_{\mathrm{h}}\right)
$$

\section{THERMODYNAMIC ANALYSIS}

The thermodynamic analysis presented here involves the application of first law of thermodynamics to an idealized operating cycle with quasi-static processes. The analysis can obtain upper bounds for selected performance indices of the system. The values in practice are expected to be lower than these estimated values due to the effects of chemical kinetics, heat transfer mechanisms, heat capacities of system components etc. The material pairs with lower estimated values might not worth a detailed study from the point of view of total energy stored unless there is change in the operating cycle.

\subsection{Operating Cycle}

The idealized operating cycle as shown in Figure 3 for which the first law of thermodynamics is applied consists of a charging and discharging sequence. For the application of the first law of thermodynamics, an infinitesimal change in the internal energy of the bed can be written as,

$$
d U=I d T+m^{\mathrm{a}} c^{\mathrm{a}} d T+m^{\mathrm{m}} c^{\mathrm{m}} d T+m^{\mathrm{g}} d u^{\mathrm{g}}+\Delta u_{\mathrm{F}} d m^{\mathrm{r}}+u^{\mathrm{g}} d \breve{m}
$$

in which the internal energy change during hydride formation including deviations from standard state is given as,

$$
\Delta u_{\mathrm{F}}=\Delta H_{\mathrm{F}}^{!}+\frac{1+w_{\mathrm{m}}^{\mathrm{r}}}{w_{m}^{\mathrm{r}}} \int_{T^{!}}^{T} c^{\mathrm{m}} d T-\frac{1}{w_{\mathrm{m}}^{\mathrm{r}}} \int_{T^{!}}^{T} c^{\mathrm{a}} d T-\left\{u^{\mathrm{g}}-\left(h^{\mathrm{g}}\right)^{!}\right\}
$$


The additional heat capacity ( $I$ ) associated with the bed can be assumed to be absent to obtain the upper bounds of performance resulting from a selected pair of materials.

\subsubsection{Modelling the effects of hysteresis}

Hysteresis in the isotherms enters the modelling of the processes when considering changing the pressure or temperature from an equilibrium state. In the case of pressure hysteresis, it is assumed that, for a hydrogen-metal/alloy system in an equilibrium state lying on the hydride decomposition curve, when the pressure is increased from the equilibrium value, hydride formation does not commence (value of reacted fraction $x$ remains unchanged) till the hydrogen pressure becomes equal to or above the equilibrium pressure value given by the hydride formation curve corresponding to the same system temperature in the $p-x$ plane. Similarly, in the case of a system in a state lying on the formation curve, when the pressure is reduced from the equilibrium value, hydride decomposition does not commence till the hydrogen pressure becomes equal to or below the equilibrium pressure value given by the decomposition curve corresponding to the system temperature.

In the case of thermal hysteresis, for a system in an equilibrium state lying on the hydride decomposition curve, when the temperature is reduced from the equilibrium value, hydride formation does not commence till the hydrogen pressure becomes equal to or above the equilibrium pressure value given by the hydride formation curve corresponding to the system temperature (which decreases during the process). Similarly, for a system in an equilibrium state lying on the formation curve, when the temperature is increased from the equilibrium value, hydride decomposition does not commence till the hydrogen pressure becomes equal to or below the equilibrium pressure value given by the formation curve corresponding to the system temperature (which increases during the process).

\subsubsection{Charging Sequence}

Process 1-2: The energy storage bed is heated by the high temperature source. The metal hydride decomposes and the released hydrogen flows into the hydrogen storage bed which is maintained at the ambient temperature. The hydrogen reacts with the metal/alloy in the hydrogen storage bed releasing heat to the ambient. Throughout the whole process, the two beds are assumed to operate at the same pressure $\left(p^{\mathrm{e}}=p^{\mathrm{h}}\right)$ which rises as the energy storage bed temperature rises. The process ends when the energy storage bed reaches the temperature of heat source. The conservation of mass and energy for the process gives,

$$
\begin{aligned}
& \left(\breve{m}_{2}^{\mathrm{e}}+\breve{m}_{2}^{\mathrm{h}}\right)-\left(\breve{m}_{1}^{\mathrm{e}}+\breve{m}_{1}^{\mathrm{h}}\right)=0 \\
& Q_{12}^{\mathrm{e}}=U_{2}^{\mathrm{e}}-U_{1}^{\mathrm{e}}-\int_{1}^{2} h^{\mathrm{eg}} d \breve{m}^{\mathrm{e}} \\
& Q_{12}^{\mathrm{h}}=U_{2}^{\mathrm{h}}-U_{1}^{\mathrm{h}}+\int_{1}^{2} h^{\mathrm{eg}} d \breve{m}^{\mathrm{e}}
\end{aligned}
$$


Process 2-3: The beds are disconnected and the energy storage bed is cooled down to the ambient temperature. The pressure in energy storage bed drops to a value lower than that in the hydrogen storage bed. The system is then referred to as charged and ready for storage.

$$
\begin{gathered}
\breve{m}_{3}^{\mathrm{e}}-\breve{m}_{2}^{\mathrm{e}}=0 \\
Q_{23}^{\mathrm{e}}=U_{3}^{\mathrm{e}}-U_{2}^{\mathrm{e}}
\end{gathered}
$$

\subsubsection{Discharging Sequence}

Process 3-4: The two beds are connected and the high pressure gas in the hydrogen storage bed is allowed to flow into and react with metal/alloy in energy storage bed. Heat is not removed from the energy storage bed till the desired temperature is reached.

$$
\left(\breve{m}_{4}^{\mathrm{e}}+\breve{m}_{4}^{\mathrm{h}}\right)-\left(\breve{m}_{3}^{\mathrm{e}}+\breve{m}_{3}^{\mathrm{h}}\right)=0
$$

This process may be allowed to proceed till the pressure in energy storage bed rises and that in hydrogen storage bed falls till both are equal. At this point of equilibrium, no further transfer of hydrogen can occur and the energy storage temperature would attain the maximum temperature possible. The peak temperature is determined by solving the differential form of energy balance for the process which can be written in terms of independent parameters $T^{\mathrm{e}}$ and $p^{\mathrm{h}}$.

$$
\frac{d T^{\mathrm{e}}}{d p^{\mathrm{h}}}=\left(\frac{\partial U^{\mathrm{e}}}{\partial T^{\mathrm{e}}}\right)_{p^{\mathrm{h}}}^{-1}\left\{-h^{\mathrm{hg}} \frac{d \breve{m}^{\mathrm{h}}}{d p^{\mathrm{h}}}-\left(\frac{\partial U^{\mathrm{e}}}{\partial p^{\mathrm{h}}}\right)_{T^{\mathrm{e}}}\right\}
$$

where,

$$
\begin{gathered}
\left(\frac{\partial U^{\mathrm{e}}}{\partial p^{\mathrm{h}}}\right)_{T^{\mathrm{e}}}=m^{\mathrm{eg}}\left(\frac{\partial u^{\mathrm{eg}}}{\partial p^{\mathrm{h}}}\right)_{T^{\mathrm{e}}}+\Delta u_{\mathrm{F}}^{\mathrm{e}}\left(\frac{\partial m^{\mathrm{er}}}{\partial p^{\mathrm{h}}}\right)_{T^{\mathrm{e}}}+u^{\mathrm{eg}} \frac{d \breve{m}^{\mathrm{h}}}{d p^{\mathrm{h}}} \\
\left(\frac{\partial U^{\mathrm{e}}}{\partial T^{\mathrm{e}}}\right)_{p^{\mathrm{h}}}=I+m^{\mathrm{ea}} c^{\mathrm{ea}}+m^{\mathrm{em}} c^{\mathrm{em}}+m^{\mathrm{eg}}\left(\frac{\partial u^{\mathrm{eg}}}{\partial T^{\mathrm{e}}}\right)_{p^{\mathrm{h}}}+\Delta u_{\mathrm{F}}^{\mathrm{e}}\left(\frac{\partial m^{\mathrm{er}}}{\partial T^{\mathrm{e}}}\right)_{p^{\mathrm{h}}}
\end{gathered}
$$

Process 4-5: If process 3-4 is not extended till the pressures are equal (desired discharge temperature lower than peak value), heat is removed while maintaining an energy storage bed at desired discharge temperature $\left(T_{\mathrm{d}}\right)$ till the pressures in the two beds are equal $\left(p^{\mathrm{e}}=p^{\mathrm{h}}\right)$.

$$
\begin{aligned}
& \left(\breve{m}_{5}^{\mathrm{e}}+\breve{m}_{5}^{\mathrm{h}}\right)-\left(\breve{m}_{4}^{\mathrm{e}}+\breve{m}_{4}^{\mathrm{h}}\right)=0 \\
& Q_{45}^{\mathrm{e}}=U_{5}^{\mathrm{e}}-U_{4}^{\mathrm{e}}+\int_{4}^{5} h^{\mathrm{hg}} d \breve{m}^{\mathrm{h}} \\
& Q_{45}^{\mathrm{h}}=U_{5}^{\mathrm{h}}-U_{4}^{\mathrm{h}}-\int_{4}^{5} h^{\mathrm{hg}} d \breve{m}^{\mathrm{h}}
\end{aligned}
$$


Process 5-1: The energy storage bed is cooled to the ambient temperature with the beds still connected and the pressures in both the beds drop together $\left(p^{\mathrm{e}}=p^{\mathrm{h}}\right)$ to the dead state pressure.

$$
\begin{aligned}
& \left(\breve{m}_{1}^{\mathrm{e}}+\breve{m}_{1}^{\mathrm{h}}\right)-\left(\breve{m}_{5}^{\mathrm{e}}+\breve{m}_{5}^{\mathrm{h}}\right)=0 \\
& Q_{51}^{\mathrm{e}}=U_{1}^{\mathrm{e}}-U_{5}^{\mathrm{e}}+\int_{5}^{1} h^{\mathrm{hg}} d \breve{m}^{\mathrm{h}} \\
& Q_{51}^{\mathrm{h}}=U_{1}^{\mathrm{h}}-U_{5}^{\mathrm{h}}-\int_{5}^{1} h^{\mathrm{hg}} d \breve{m}^{\mathrm{h}}
\end{aligned}
$$

\subsection{Performance indices}

Volumetric energy storage density:

$$
\zeta=\frac{Q_{\mathrm{d}}}{V^{\mathrm{e}}+V^{\mathrm{h}}}
$$

where, $Q_{\mathrm{d}}=Q_{45}+Q_{51}$. The volumetric storage density is based on the total system volume.

Energy storage efficiency:

$$
\eta=\frac{Q_{\mathrm{d}}}{Q_{\mathrm{h}}}
$$

where, $Q_{\mathrm{h}}=Q_{12}$.

Peak discharge temperature: This denotes the peak value of temperature $T_{\mathrm{m}}^{\mathrm{e}}$ that can be attained by discharging the system. This is determined as the energy storage bed temperature after allowing the process 3-4 during the discharge sequence to continue till the gas pressure in both the beds become equal.

\section{HEAT AND MASS TRANSFER ANALYSIS}

The estimates of upper bounds of performance indices obtained from thermodynamic analysis can be improved by including the reaction kinetics of hydrogen-metal/alloy system. The analysis presented here is similar to those presented and validated by Bjurström, and S. Suda [8], Gambini [9], Mellouli et al. [10] and includes hysteresis effects during the processes modelled similarly to the work by Yang, Zhang and Bao [11]. Each one of the two beds as shown in Figure 4, is approximated by a lumped system exchanging heat with a heat transfer fluid. Hydrogen gas is flows back and forth between the beds during the charging and discharging processes.

The bed state at any point of time can be completely described by three variables which were chosen to be $x, T$ and $\rho^{\mathrm{g}}$. The balance of energy for a bed can be written as follows. 


$$
\frac{d Q}{d t}=\frac{d U}{d t}-h_{\mathrm{h}} \frac{d \breve{m}}{d t}
$$

where, $h_{\mathrm{h}}$ is the specific enthalpy of gaseous hydrogen in the bed with the higher pressure among the two beds (which will have a negative value of change in total hydrogen mass $\breve{m}$ ).

The rate equations for different quantities can be written as follows.

- The heat exchanger behaviour in both the beds is approximated by a quasi-steady state model based on number of transfer units (NTU). Heat transfer rate to a bed at temperature $T$ is given by,

$$
\dot{Q}=\frac{d Q}{d t}=C_{\mathrm{f}}\left(T_{\mathrm{fi}}-T_{\mathrm{fo}}\right)
$$

where,

$$
T_{\mathrm{fo}}=T+\left(T_{\mathrm{fi}}-T\right) \exp \left(-\frac{K}{C_{\mathrm{f}}}\right)
$$

- The mass flow rate between the beds $\left(\dot{m}_{\mathrm{H}}\right)$ is described in terms of change in total hydrogen mass $\breve{m}_{\mathrm{h}}$ of the bed with higher pressure $p_{\mathrm{h}}$ at the instant of interest. If a parameter $a$ is specified as the area across which flow occurs (approximation for the cross-sectional area of line connecting the beds) and the flow is approximated by an isentropic flow with specific entropy $s_{\mathrm{h}}$ in the reactor with high pressure, the change in total hydrogen mass in the reactor with higher pressure can be written as,

$$
\frac{d \breve{m}_{\mathrm{h}}}{d t}=-\rho^{\mathrm{g}}\left(p_{1}, s_{\mathrm{h}}\right) a v
$$

where,

$$
v=\sqrt{2\left\{h_{\mathrm{h}}-h\left(p_{1}, s_{\mathrm{h}}\right)\right\}}
$$

The value of $p_{1}$ is the lower bed pressure as long as $v$ is subsonic and is limited on the lower side by the value of pressure at which $v$ becomes sonic.

The upper limit of mass flow rate during discharge process is restricted further (in addition to sonic limit) by a specified value to simulate gas flow control during discharge process.

- The rate of change of internal energy can be written as,

$$
\frac{d U}{d t}=I \frac{d T}{d t}+m^{\mathrm{a}} c^{\mathrm{a}} \frac{d T}{d t}+m^{\mathrm{m}} c^{\mathrm{m}} \frac{d T}{d t}+m^{\mathrm{g}} \frac{d u^{\mathrm{g}}}{d t}+\Delta u_{\mathrm{F}} \tilde{m} w_{\mathrm{m}}^{\mathrm{r}} \frac{d x}{d t}+u^{\mathrm{g}} \frac{d \breve{m}}{d t}
$$


The change in specific internal energy of the hydrogen gas in bed can be written as,

$$
\frac{d u^{\mathrm{g}}}{d t}=\left(\frac{\partial u^{\mathrm{g}}}{\partial \rho^{\mathrm{g}}}\right)_{T} \frac{d \rho^{\mathrm{g}}}{d t}+\left(\frac{\partial u^{\mathrm{g}}}{\partial T}\right)_{\rho^{\mathrm{g}}} \frac{d T}{d t}
$$

where, the derivatives of specific internal energy of hydrogen can be obtained from properties of hydrogen gas. From Equation (1),

$$
\frac{d \rho^{\mathrm{g}}}{d t}=\frac{1}{V^{\mathrm{v}}}\left(\frac{d \breve{m}}{d t}-\tilde{m} w_{\mathrm{m}}^{\mathrm{r}} \frac{d x}{d t}\right)
$$

The energy balance can then be written as,

$$
\frac{d T}{d t}=\frac{1}{Z}\left\{\frac{d Q}{d t}-m^{\mathrm{g}}\left(\frac{\partial u^{\mathrm{g}}}{\partial \rho^{\mathrm{g}}}\right)_{T} \frac{d \rho^{\mathrm{g}}}{d t}-\tilde{m} w_{\mathrm{m}}^{\mathrm{r}} \Delta u_{\mathrm{F}} \frac{d x}{d t}+\left(h_{\mathrm{h}}-u^{\mathrm{g}}\right) \frac{d \breve{m}}{d t}\right\}
$$

where,

$$
Z=I+m^{\mathrm{a}} c^{\mathrm{a}}+m^{\mathrm{m}} c^{\mathrm{m}}+m^{\mathrm{g}}\left(\frac{\partial u^{\mathrm{g}}}{\partial T}\right)_{\rho^{\mathrm{g}}}
$$

Equations (31), (30) and (4) when applied for both the beds, form a system of six first order ordinary differential equations and when solved simultaneously with the following condition for mass balance, gives the temporal behaviour of the system.

$$
\frac{d \breve{m}^{\mathrm{e}}}{d t}+\frac{d \breve{m}^{\mathrm{h}}}{d t}=0
$$

For the heat and mass transfer analysis, the mass flow rate of hydrogen is set to zero during the cooling process in the charging sequence (process 2-3). The heat transfer rate to energy storage bed is set to zero during the process $3-4$. The processes 4-5 and 5-1 are combined to a single cooling process. The heat supply (or removal) is achieved by switching the inlet fluid temperatures to the high temperature (or low temperature) value.

\section{APPLICATION TO LaNi $_{4.7} \mathbf{A l}_{0.3}-\mathrm{LaNi}_{5}$ SYSTEM}

The $\mathrm{LaNi}_{4.7} \mathrm{Al}_{0.3}$ bed in the system acts as the energy storage bed and the $\mathrm{LaNi}_{5}$ as the hydrogen storage. The heat source is taken as a reservoir at $353 \mathrm{~K}$ and the ambient temperature as $303 \mathrm{~K}$. The system parameters are the dead state pressure and the ratio $(\xi)$ between the volume of hydrogen storage bed and that of energy storage bed. 


\subsection{Computation}

The entire calculation was coded as a Python ${ }^{\mathrm{TM}}$ program making use of integration and optimization algorithms from SciPy [12]. The data for states of hydrogen gas were obtained from CoolProp [13], a software database, which provides fully featured wrappers for Python ${ }^{\mathrm{TM}}$. The results from the code were plotted using Matplotlib [14], a Python ${ }^{\mathrm{TM}}$ plotting library.

\subsection{Properties of materials}

The thermo-physical properties of metals are given in Table 1. The porosities are evaluated to match packing densities from Supper et al. [15] and Goudy et al. [16].

The specific heat of the metal/hydride is estimated from that of the metal/alloy using the Neumann-Kopp rule as follows.

$$
c^{\mathrm{m}}=\frac{c^{\mathrm{a}}+w_{\mathrm{m}}^{\mathrm{r}} c_{\mathrm{H}}}{1+w_{\mathrm{m}}^{\mathrm{r}}}
$$

where, the specific heat capacity of hydrogen $c_{\mathrm{H}}$ is taken as $1.02 \times 10^{4} \mathrm{Jkg}^{-1} \mathrm{~K}^{-1}$, the value at pressure 1 bar and temperature $298.15 \mathrm{~K}$.

The $p-x-T$ characteristics for both the materials obtained from Nishizaki et al. [21] has the following form with parameters listed in Table 2 .

$$
\ln \left(\frac{p}{p^{!}}\right)=A-\frac{B}{T}+(\phi \pm \tilde{\phi}) \tan \{\pi(x-0.5)\} \pm \frac{\beta}{2}
$$

(+) for formation and (-) for decomposition of hydride.

Equation (34) has the third and fourth term corresponding to the plateau slope and hysteresis respectively, overlaid on the van't Hoff equation. The enthalpy change and entropy change for the hydride formation reaction can be estimated from $A$ and $B$.

The reaction kinetics is described by the following equations provided by Mayer et al. [22] with parameters provided in Table 3 (assumed to be same for formation and decomposition),

$$
\frac{d x}{d t}= \begin{cases}\sigma_{\mathrm{F}} \exp \left(-\frac{E_{\mathrm{F}}}{R T}\right) \ln \left(\frac{p}{p_{\mathrm{eF}}}\right) \cdot(1-x) & \text { for formation } \\ \sigma_{\mathrm{D}} \exp \left(-\frac{E_{\mathrm{D}}}{R T}\right) \frac{p-p_{\mathrm{eD}}}{p_{\mathrm{eD}}} \cdot x & \text { for decomposition }\end{cases}
$$

\section{RESULTS AND DISCUSSION}

The operating cycle with quasi-static processes for a dead state pressure of 2 bar and a bed volume ratio of 0.7 is shown in the $p-x$ planes of $\mathrm{LaNi}_{4.7} \mathrm{Al}_{0.3}$ and $\mathrm{LaNi}_{5}$ in Figure 5 and Figure 6 along with 
isotherms of formation and decomposition at the selected temperature. State 2 is achieved by decomposing the $\mathrm{LaNi}_{4.7} \mathrm{Al}_{0.3}$ hydride by heating the energy storage bed and is expected to lie on the decomposition isotherm for $\mathrm{LaNi}_{4.7} \mathrm{Al}_{0.3}$ at $353 \mathrm{~K}$. State 3 is reached after cooling down from state 2 and some of the hydrogen gas in the void is expected to recombine with the metal/alloy and therefore state 3 lies on the hydride formation isotherm at $303 \mathrm{~K}$. The discharge process $3-1$ is shown in three steps- raising the temperature to a selected value of $313 \mathrm{~K}$ (state 4), isothermal discharge at $313 \mathrm{~K}$ till the pressures in the beds equalize (state 5) and cooling down to $303 \mathrm{~K}$ back to dead state (state 1 ).

The computed values of performance indices for various values of system parameters are depicted in Figure 7 to Figure 10. It can be seen from Figure 7 that there is a range of values of dead state pressure within which the volumetric energy density can achieve high values close to $2 \times 10^{8} \mathrm{Jm}^{-3}$ (about $56 \mathrm{kWhm}^{-3}$ ). This would be equivalent to $0.02 \mathrm{kWhkg}^{-1}$ of $\mathrm{LaNi}_{4.7} \mathrm{Al}_{0.3}$ while the usual estimate by multiplying the hydrogen capacity $\left(0.0143 \mathrm{kgkg}^{-1}\right)$ with the heat of reaction $\left(4.7 \mathrm{kWhkg}^{-1}\right.$ of reacted $\mathrm{H}_{2}$ ) would give close to $0.07 \mathrm{kWhkg}^{-1}$. The high values correspond to the range of dead pressures within which the reacted fraction of hydrogen in $\mathrm{LaNi}_{4.7} \mathrm{Al}_{0.3}$ bed goes to lowest values after heating (thereby enabling higher values of heat during discharge). The data also shows that within the limited pressure range, the volumetric storage density increases and then decreases when the bed volume ratio is varied from the lowest value of selected range to the highest. The detailed variation shown in Figure 8 indicates that there exists an optimum bed volume ratio (close to 0.7) about which the volumetric storage density can achieve high values. The rise in volumetric storage density at lower values of bed volume ratio can be attributed low values of reacted fraction after heating. As the bed volume ratio increases further to the highest values of the selected range, the effects of increasing system volume dominates and lower the volumetric energy storage density.

The energy storage efficiency and peak discharge temperature also can achieve high values only in a limited pressure range as shown in Figure 9 and Figure 10. Within this pressure range, both of these quantities rise monotonically with bed volume ratio before reaching a maximum (about 0.85 for energy storage efficiency and $343 \mathrm{~K}$ for peak temperature) beyond which a change bed volume ratio has almost no effect.

For materials with acceptable values of the upper bounds, the present analysis involving only the $p-x-T$ characteristics and hydrogen properties, also provides a range of system parameter values within which the maximum performance can be expected. This aids in restricting further detailed studies to relatively smaller set of operating conditions.

The heat and mass transfer analysis, obviously, is computationally more expensive than the thermodynamic analysis and was carried out with system parameter values close to those corresponding to the peak performance from thermodynamic analysis. The cycle was assumed to be for a long term storage where the system has sufficient time to achieve equilibrium (dead state) after 
each cycle. The bed volumes for energy storage bed and hydrogen storage bed were chosen to be $7 \times 10^{-3} \mathrm{~m}^{-3}$ and $5 \times 10^{-3} \mathrm{~m}^{-3}$ respectively (a bed volume ratio close to 0.7 ). The dead state pressure was chosen as $1.5 \times 10^{5} \mathrm{~Pa}$. A representative set of process timings, namely $3500 \mathrm{~s}, 500 \mathrm{~s}$, 600s and $3500 \mathrm{~s}$ respectively, for processes 1-2, 2-3, 3-4 and 4-1 (based on time required for rate of reaction in each process to drop by about an order of magnitude of the peak value and the computational effort required at very low reaction rates). The values of heat capacity rate is for heat exchangers in both the beds were set to $1500 \mathrm{WK}^{-1}$ and the overall heat conductance to $150 \mathrm{WK}^{-1}$. These values were kept on the higher side to ensure that the analysis provides an estimate of peak performance of the system. The area for hydrogen flow was set to $6 \times 10^{-4} \mathrm{~m}^{2}$ and the hydrogen mass flow during the discharge sequence (from hydrogen storage bed to energy storage bed) was limited on the higher side to $5 \times 10^{-5}$ $\mathrm{kgs}^{-1}$.

Figure 11, Figure 12, Figure 13, and Figure 14 shows the variation of temperature, fraction of reacted hydrogen, pressure and rate of reaction respectively, during the cycle. The peak temperature attained by the energy storage bed is about $334 \mathrm{~K}$. The heating process $1-2$ in the charging sequence occurs with almost equal pressures in both the beds. During the temperature raising process 3-4 in the discharge sequence, the bed pressure values equalize within a short time and continue to rise together as temperature in the energy storage bed rises due to heat liberated by the hydride formation reaction. The heat transfer rates during process 1-2 and process 4-1 were integrated over the respective time intervals to obtain heat input and output values, $2.3 \times 10^{6} \mathrm{~J}$ and $1.7 \times 10^{6} \mathrm{~J}$. The corresponding values of performance indices are about $40 \mathrm{kWhm}^{-3}$ for volumetric energy storage density and $73 \%$ for energy storage efficiency. The values of performance indices are considerably lower than those predicted using the thermodynamic analysis.

\section{CONCLUSIONS}

The thermodynamic analysis presented above can help in screening working pairs of metals/alloys by looking for compatible characteristics and based on upper bounds of performance indices thereby identifying ones which show promise when working in a two bed thermal energy storage system without active pumping of hydrogen. Addition of any further complexities such as chemical kinetics, heat transfer etc., will bring down the predicted performance. The study can therefore save effort put into detailed and more time consuming studies which consider these complexities. The heat and mass transfer analysis considering the reaction kinetics, hydrogen flow between the beds and heat exchanger models provides a second level estimate of the performance indices. 


\section{ACKNOWLEDGEMENTS}

This research is based upon work supported by the US-India Partnership to Advance Clean EnergyResearch (PACE-R) for the Solar Energy Research Institute for India and the U.S. (SERIIUS) funded jointly by the U.S. Department of Energy subcontract DE AC36-08G028308 (Office of Science, Office of Basic Energy Sciences, and Energy Efficiency and Renewable Energy, Solar Energy Technology Program, with support from the Office of International Affairs) and the Government of India subcontract IUSSTF/JCERDC-SERIIUS/2012 dated 22nd Nov. 2012.

\section{REFERENCES}

[1] S. Srinivasa Murthy, Heat and mass transfer in solid state hydrogen storage: A review, Journal of Heat Transfer (ASME) 134 (2012) 031020-1-031020-11.

[2] S. Srinivasa Murthy, E. Anil Kumar, Advanced materials for solid state hydrogen storage: Thermal engineering issues, Applied Thermal Engineering 72 (2014) 176-189.

[3] M. Ram Gopal, S. Srinivasa Murthy, Studies on heat and mass transfer in metal hydride beds, International Journal of Hydrogen Energy 20(11) (1995) 911-917.

[4] D. M. Gruen, I. Sheft, Metal hydride systems for solar energy conversion and storage, Proceedings, NSF-ERDA, Workshop on Solar Heating and Cooling of Buildings, Charlottesville, Va., 1975.

[5] I. Sheft, D. M. Gruen, G. J. Lamich, L. W. Carlson, A. E. Knox, J. M. Nixon, M. H. Mendelsohn, HYCSOS-A system for evaluation of hydrides as chemical heat pumps., Hydrides for Energy Storage, Vol. 1, 551-567.

[6] J. Toepler, O. Bernauer, H. Buchner, The use of hydrides in motor vehicles, Journal of the Less Common Metals 74(2) (1980) 385-399. doi: 10.1007/bf02833425

[7] M. Wierse, R. Werner, M. Groll, Magnesium hydride for thermal energy storage in a small-scale solar-thermal power station, Journal of the Less Common Metals 172 (1991) 1111-1121. doi: $10.1016 / \mathrm{s} 0022-5088(06) 80018-4$

[8] H. Bjurström, S. Suda, The metal hydride heat pump: Dynamics of hydrogen transfer, International Journal of Hydrogen Energy 14(1) (1989) 19-28. doi: 10.1016/03603199(89)90152-3

[9] M. Gambini, Metal hydride energy systems performance evaluation. Part A: Dynamic analysis model of heat and mass transfer, International Journal of Hydrogen Energy, 19(1) (1994) 67-80. doi: 10.1016/0360-3199(94)90179-1

[10] S. Mellouli, F. Askri, H. Dhaou, A. Jemni, S. Ben Nasrallah, Parametric studies on a metal hydride cooling system, International Journal of Hydrogen Energy 34(9) (2009) 3945-3952. doi: 10.1016/j.ijhydene.2009.03.010 
[11] F. S. Yang, Z. X. Zhang, Z. W. Bao, An extensive parametric analysis on the performance of a single-stage metal hydride heat transformer, International Journal of Hydrogen Energy 37(3) (2012) 2623-2634. doi: 10.1016/j.jhydene.2011.11.007

[12] E. Jones, T. Oliphant, P. Peterson, et al., SciPy: Open source scientific tools for Python, http://www.scipy.org/, 2001, [Online; accessed 2015-06-02].

[13] I. H. Bell, J. Wronski, S. Quoilin, V. Lemort, Pure and pseudo-pure fluid thermophysical property evaluation and the open-source thermophysical property library CoolProp, Industrial \& Engineering Chemistry Research 53(6) (2014) 2498-2508. doi: 10.1021/ie4033999

[14] J. D. Hunter, Matplotlib: A 2D graphics environment, Computing in Science \& Engineering 9(3) (2007) 90-95 doi: 10.1109/mcse.2007.55

[15] W. Supper, M. Groll, U. Mayer, Reaction kinetics in metal hydride reaction beds with improved heat and mass transfer, Journal of the Less Common Metals 104(2)(1984) 279-286. doi: $10.1016 / 0022-5088(84) 90412-0$

[16] A. J. Goudy, D. G. Stokes, J. A. Gazzillo, The effect of heat transfer on the desorption kinetics of $\mathrm{LaNi}_{5} \mathrm{H}_{6}$, Journal of the Less Common Metals 91(1) (1983) 149-158. doi: 10.1016/00225088(83)90103-0

[17] E. L. Huston, G. D. Sandrock, Engineering properties of metal hydrides, Journal of the Less Common Metals 74(2) (1980) 435-443. doi: 10.1016/0022-5088(80)90182-4

[18] V. K. Sharma, E. A. Kumar, Effect of measurement parameters on thermodynamic properties of La-based metal hydrides, International Journal of Hydrogen Energy 39(11) (2014) 5888-5898. doi: 10.1016/j.ijhydene.2014.01.174

[19] Pierre Villars. Material Phases Data System (MPDS), CH-6354 Vitznau, Switzerland; SpringerMaterials; sd 0544162 (Springer-Verlag GmbH, Heidelberg, 2014). http://materials.springer.com/isp/crystallographic/docs/sd_0544162. [Online; accessed 14-062015].

[20] Pierre Villars. Material Phases Data System (MPDS), CH-6354 Vitznau, Switzerland; SpringerMaterials; sd 1920181 (Springer-Verlag GmbH, Heidelberg, 2014). http://materials.springer.com/isp/crystallographic/docs/sd_1920181. [Online; accessed 14-062015].

[21] T. Nishizaki, K. Miyamoto, K. Yoshida, Coefficients of performance of hydride heat pumps, Journal of the Less Common Metals 89(2) (1983) 559-566. doi: 10.1016/0022-5088(83)90372-7

[22] U. Mayer, M. Groll, W. Supper, Heat and mass transfer in metal hydride reaction beds: Experimental and theoretical results, Journal of the Less Common Metals 131(1) (1987) 235244. doi: 10.1016/0022-5088(87)90523-6

[23] P. Muthukumar, A. Satheesh, M. Linder, R. Mertz, M. Groll, Studies on hydriding kinetics of some La-based metal hydride alloys, International Journal of Hydrogen Energy 34(17) (2009) 7253-7262. doi: 10.1016/j.ijhydene.2009.06.075 


\section{LIST OF FIGURES}

Figure 1. Schematic of operation of a basic thermal energy storage system

Figure 2. Change in fraction of reacted hydrogen in the two beds before and after heating

Figure 3. Representative states of beds in the idealized cycle

Figure 4. System variables for heat and mass transfer analysis

Figure 5. Operating cycle in $p-x$ plane of $\mathrm{LaNi}_{4.7} \mathrm{Al}_{0.3}$ along with characteristic isotherms exhibiting hysteresis

Figure 6. Operating cycle in $p-x$ plane of $\mathrm{LaNi}_{5}$ along with characteristic isotherms exhibiting hysteresis

Figure 7. Volumetric energy storage density for different dead state pressure at different bed volume ratios

Figure 8. Volumetric energy storage density for different bed volume ratios at different dead state pressures

Figure 9. Energy storage efficiency for different dead state pressure at different bed volume ratios

Figure 10. Peak discharge temperature for different dead state pressures at different bed volume ratios

Figure 11. Variation in bed temperatures in the beds

Figure 12. Variation in fraction of reacted hydrogen the beds

Figure 13. Variation in hydrogen pressure in the beds

Figure 14. Variation in rate of reaction in the beds 
Energy storage bed

Hydrogen storage bed
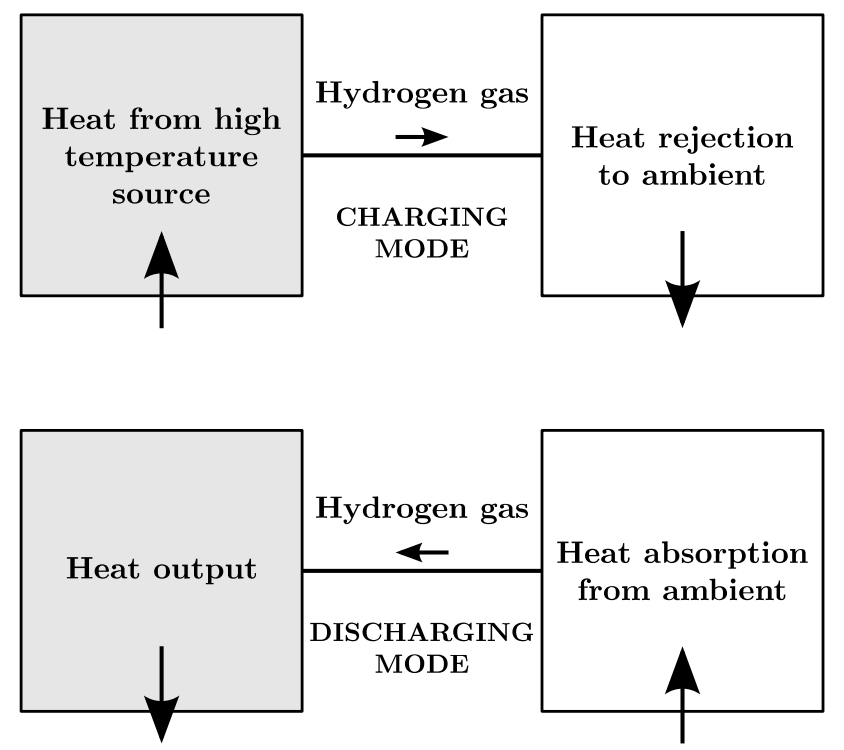

Figure 1. Schematic of operation of a basic thermal energy storage system 


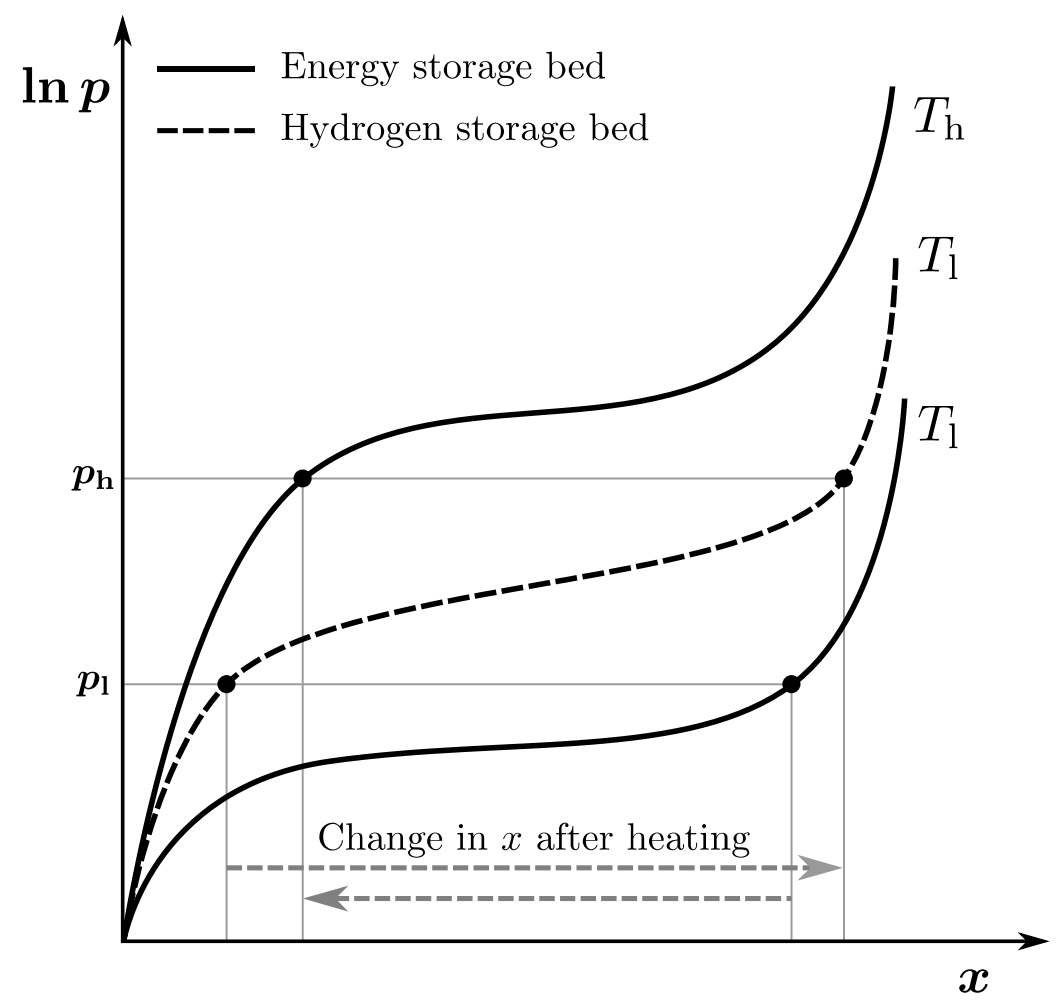

Figure 2. Change in fraction of reacted hydrogen in the two beds before and after heating 


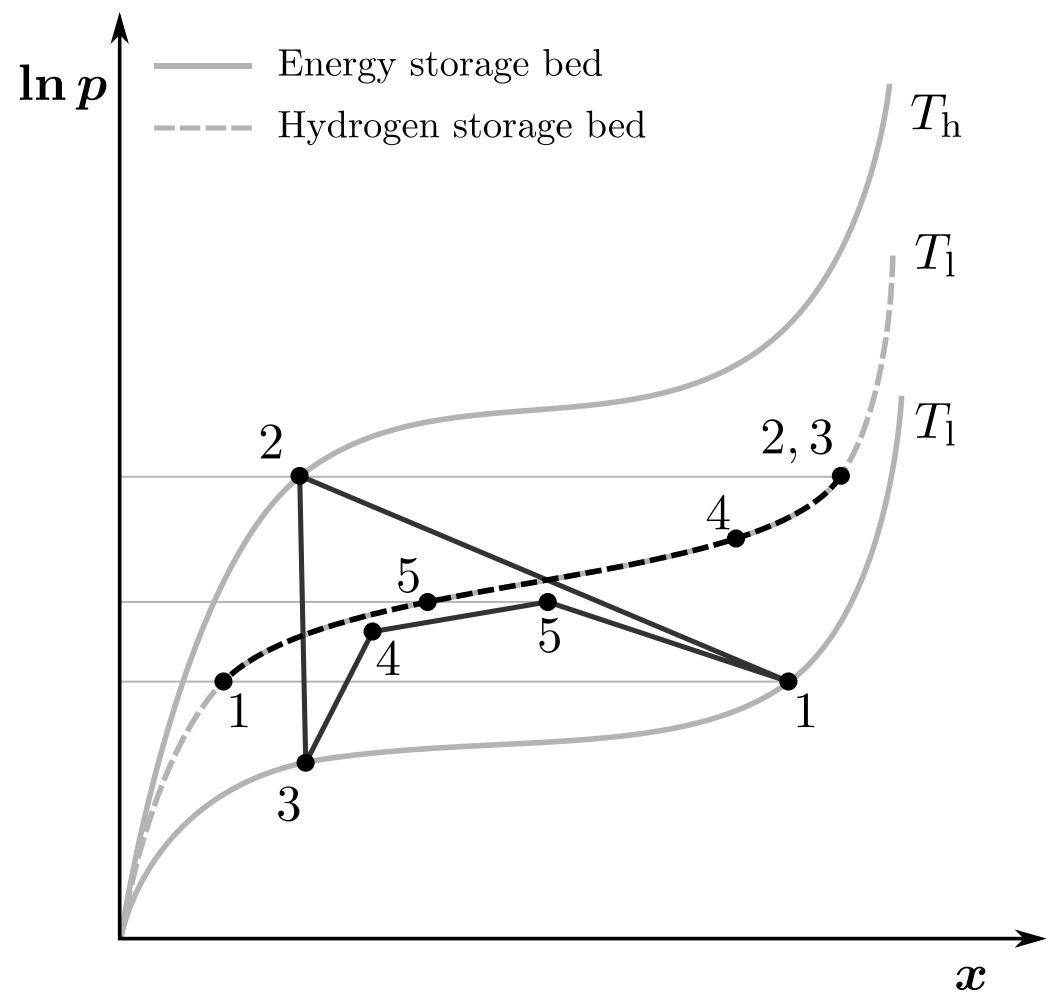

Figure 3. Representative states of beds in the idealized cycle 


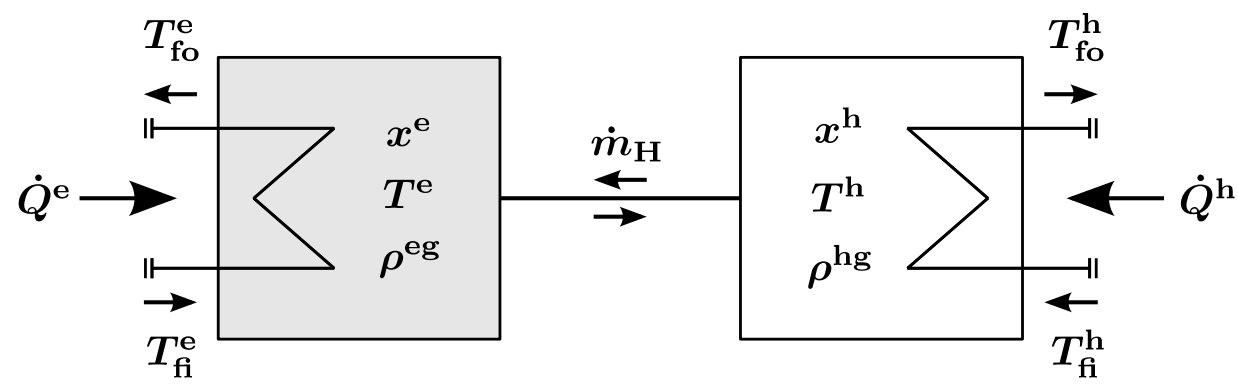

Energy storage bed

Hydrogen storage bed

Figure 4. System variables for heat and mass transfer analysis 


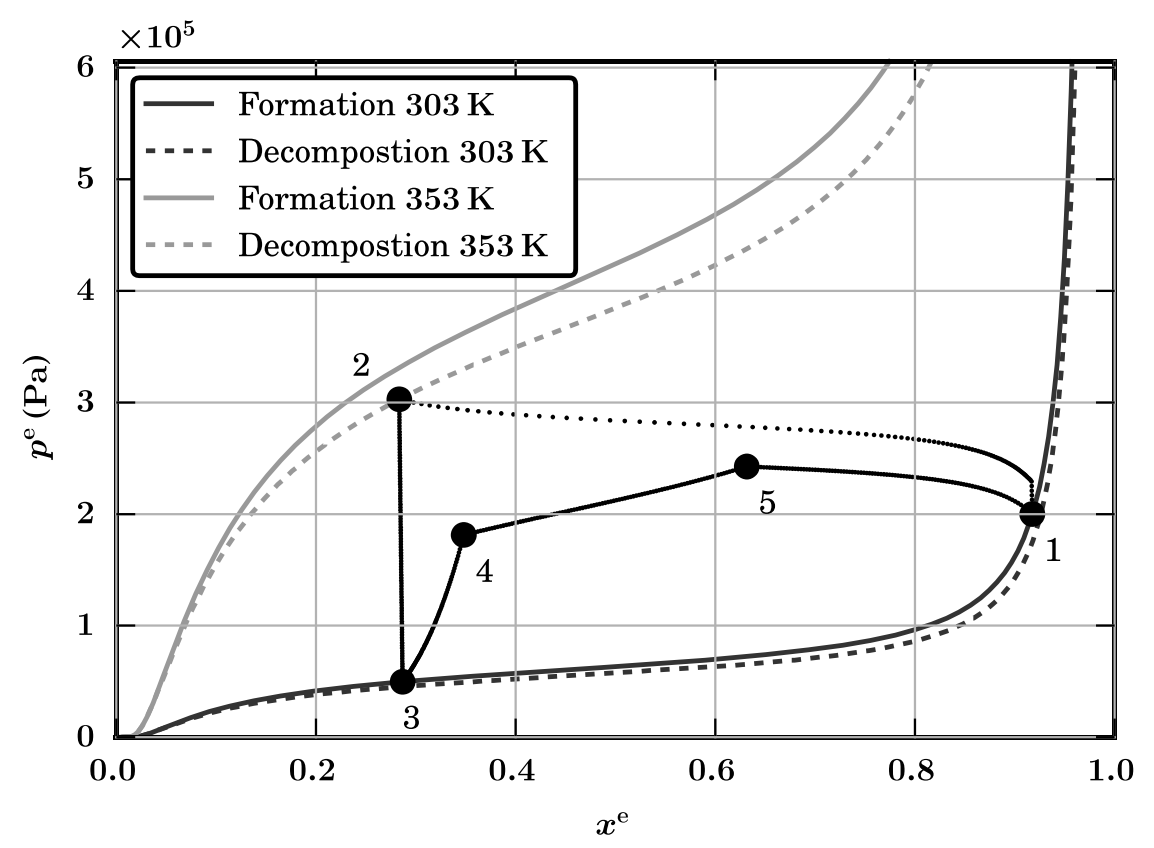

Figure 5. Operating cycle in $p-x$ plane of $\mathrm{LaNi}_{4.7} \mathrm{Al}_{0.3}$ along with characteristic isotherms exhibiting hysteresis 


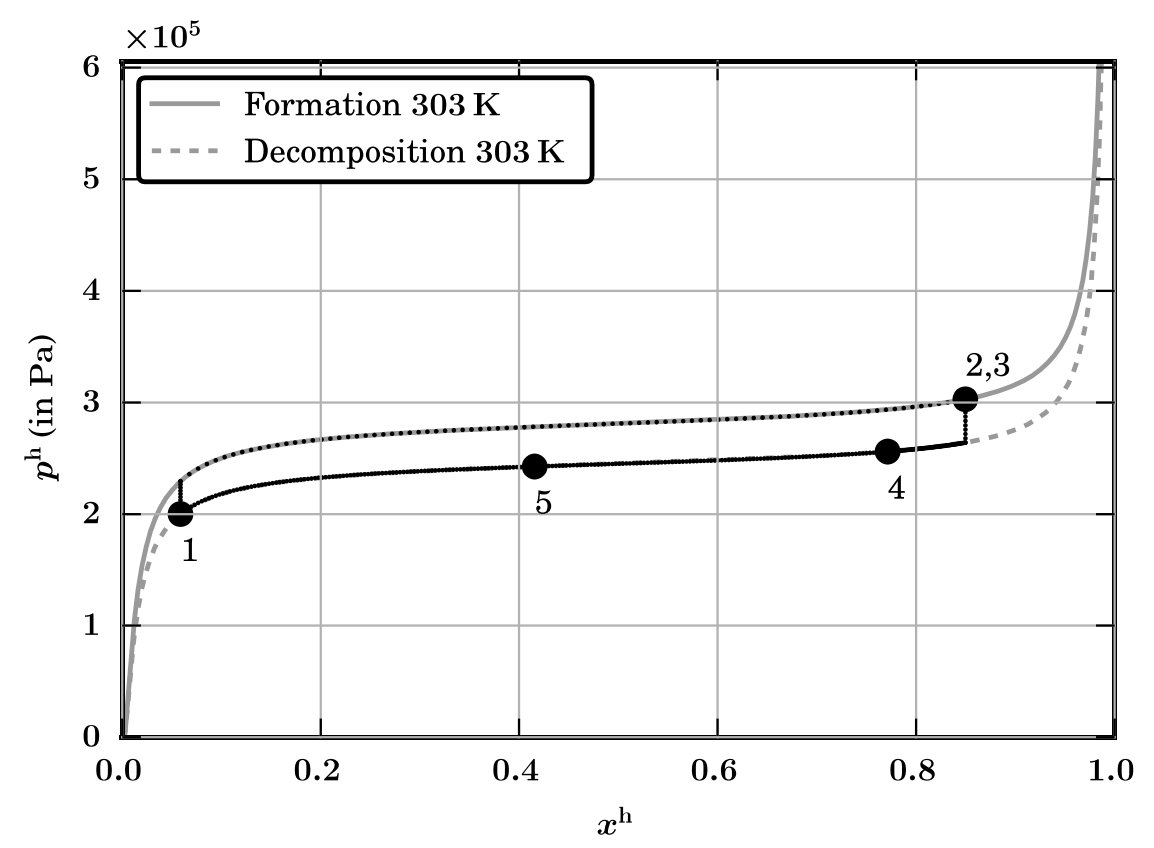

Figure 6. Operating cycle in $p-x$ plane of $\mathrm{LaNi}_{5}$ along with characteristic isotherms exhibiting hysteresis 


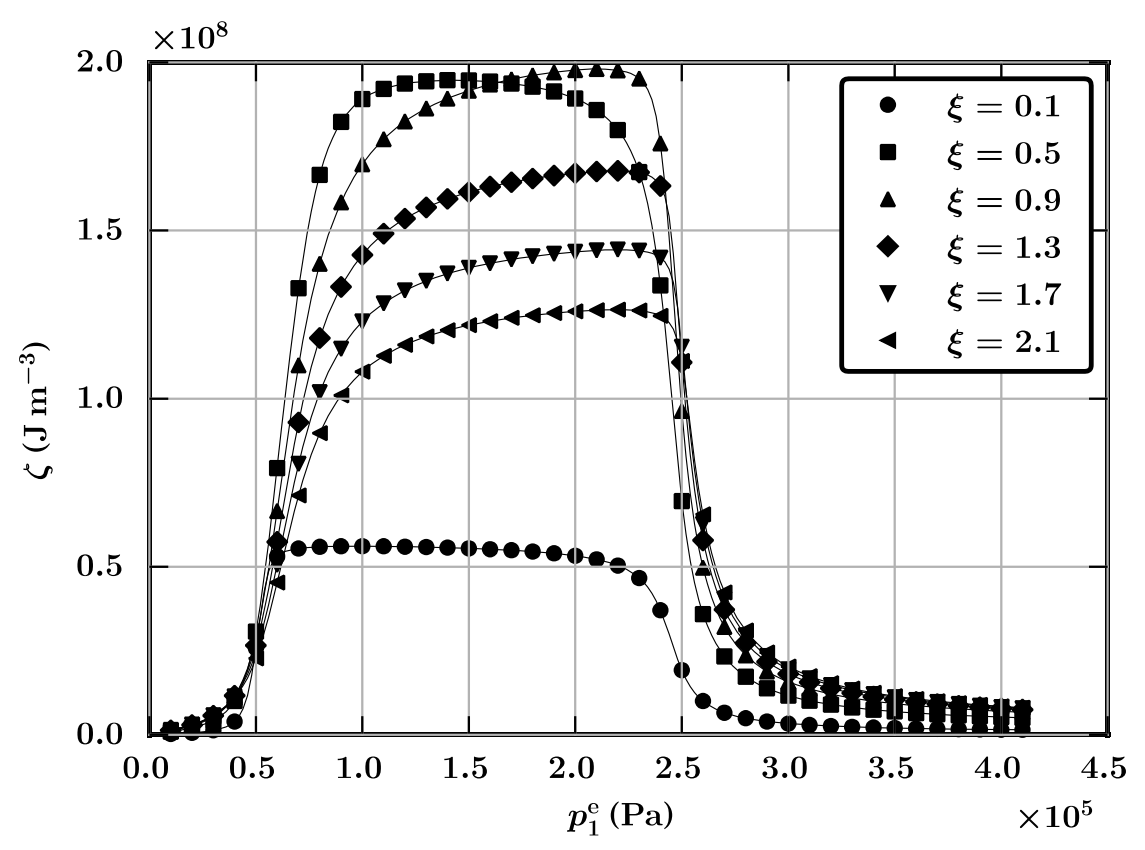

Figure 7. Volumetric energy storage density for different dead state pressure at different bed volume ratios 


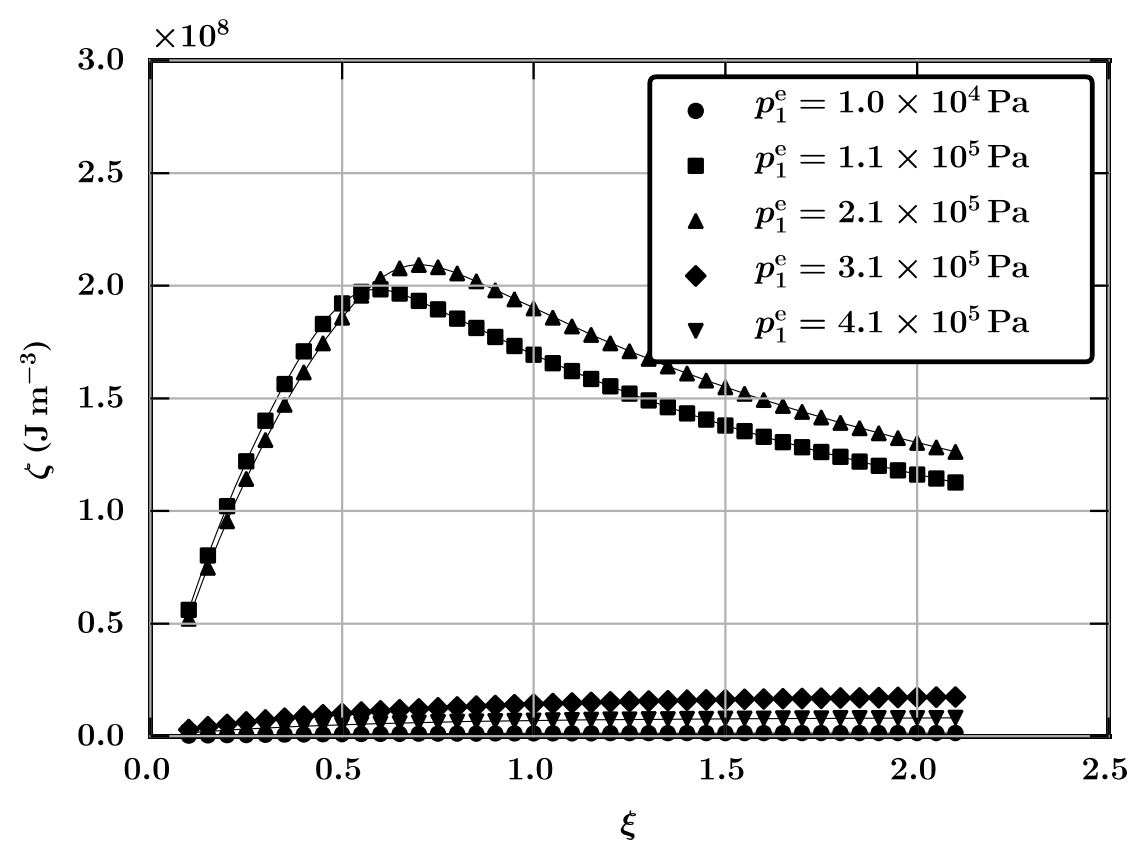

Figure 8. Volumetric energy storage density for different bed volume ratios at different dead state pressures 


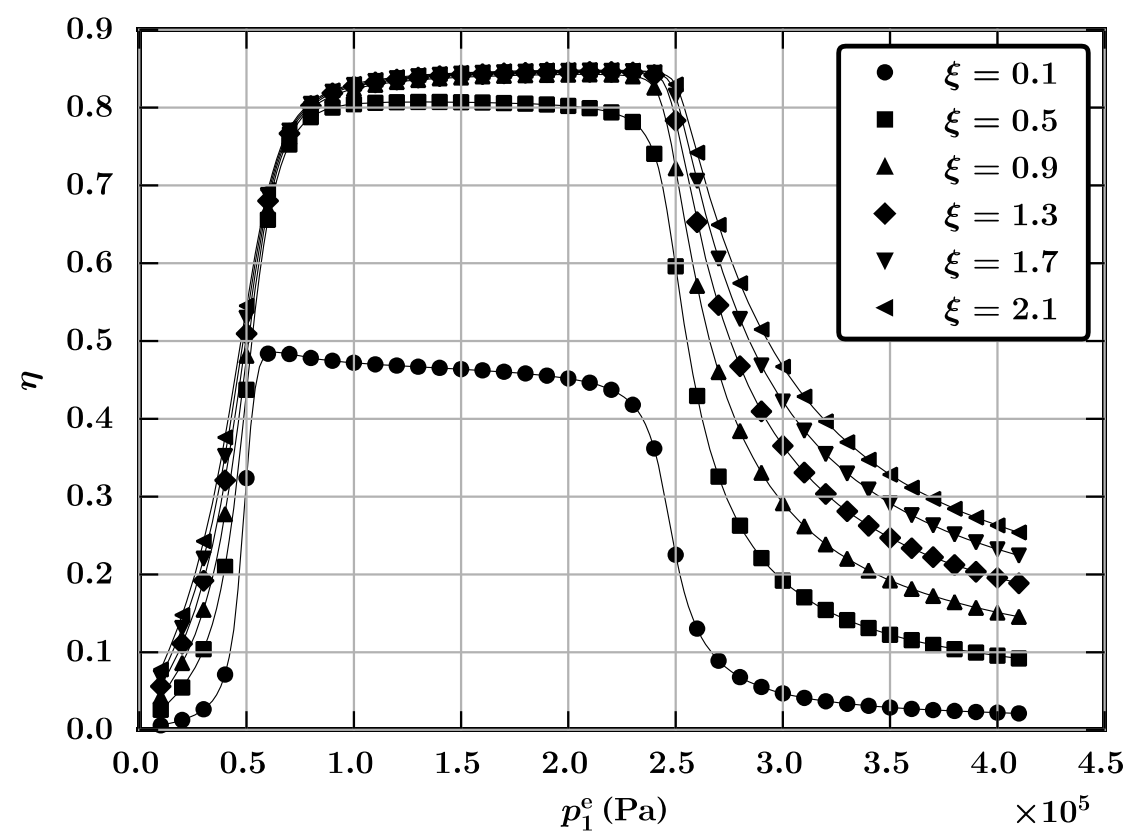

Figure 9. Energy storage efficiency for different dead state pressure at different bed volume ratios 


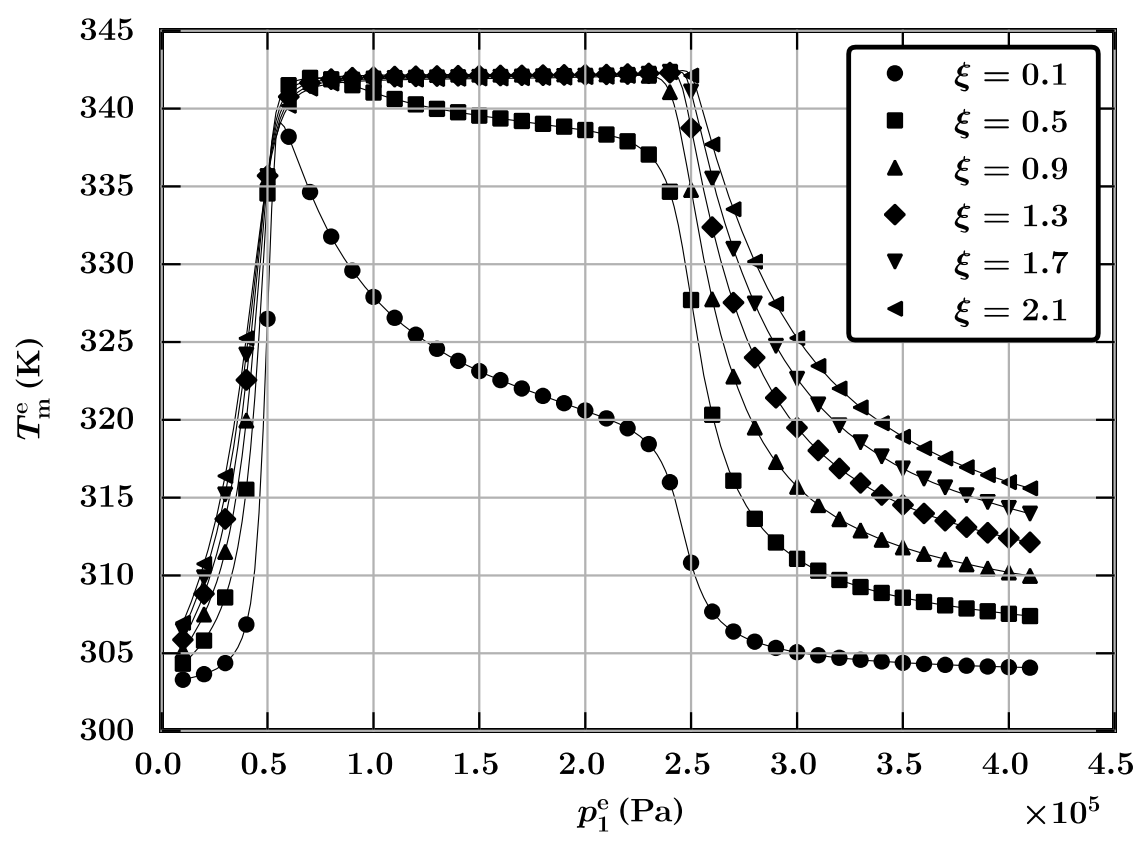

Figure 10. Peak discharge temperature for different dead state pressures at different bed volume ratios 


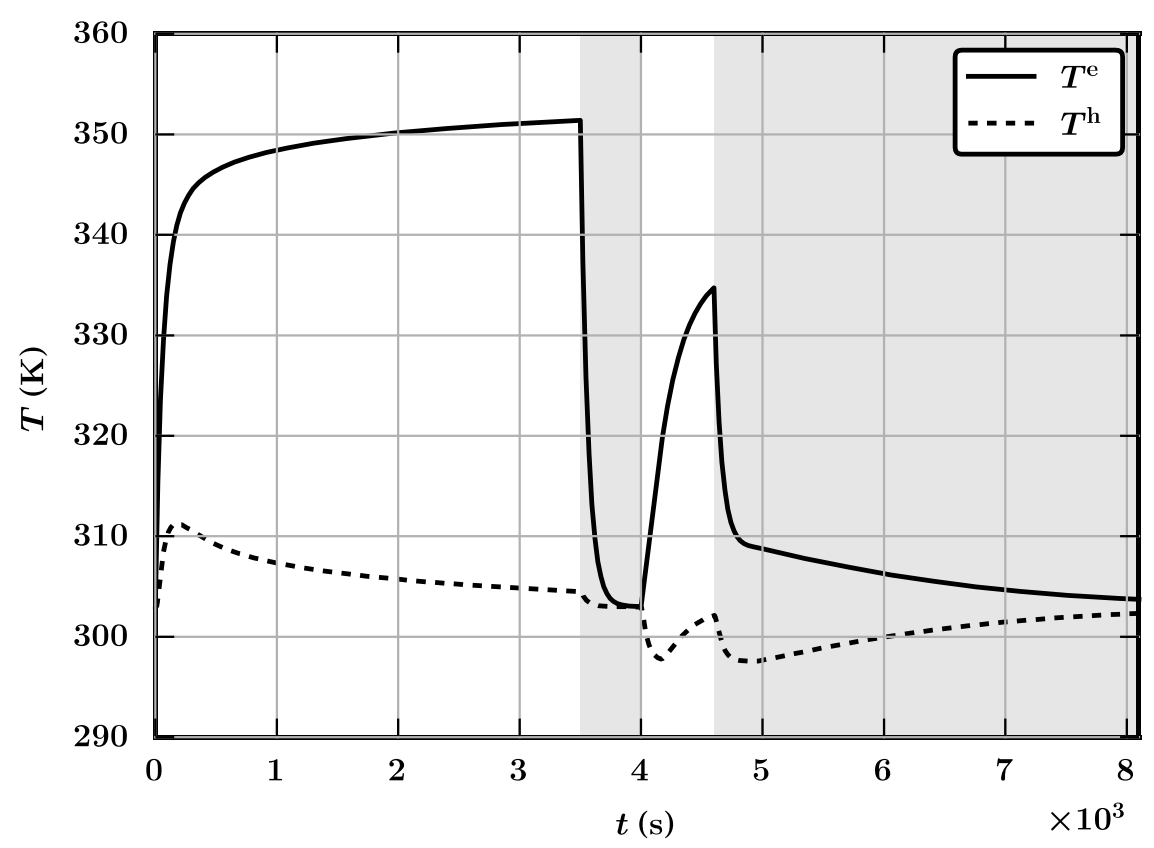

Figure 11. Variation in bed temperatures in the beds 


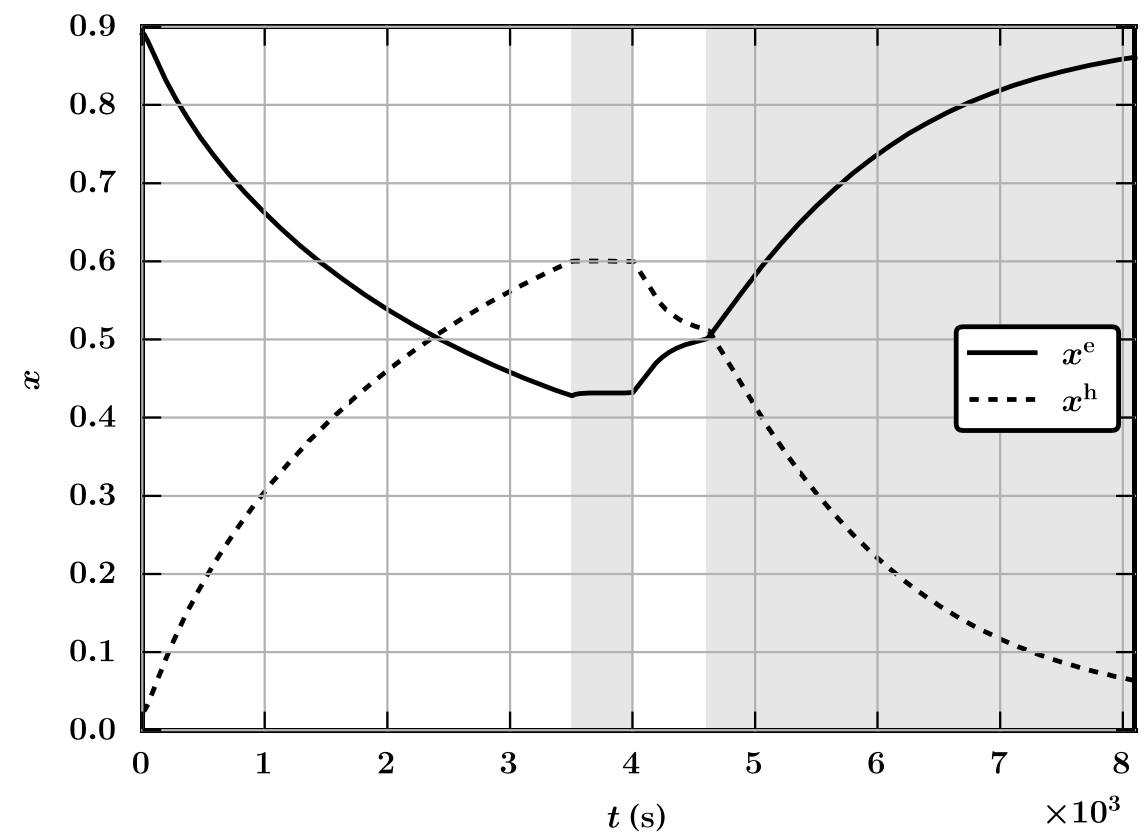

Figure 12. Variation in fraction of reacted hydrogen the beds 


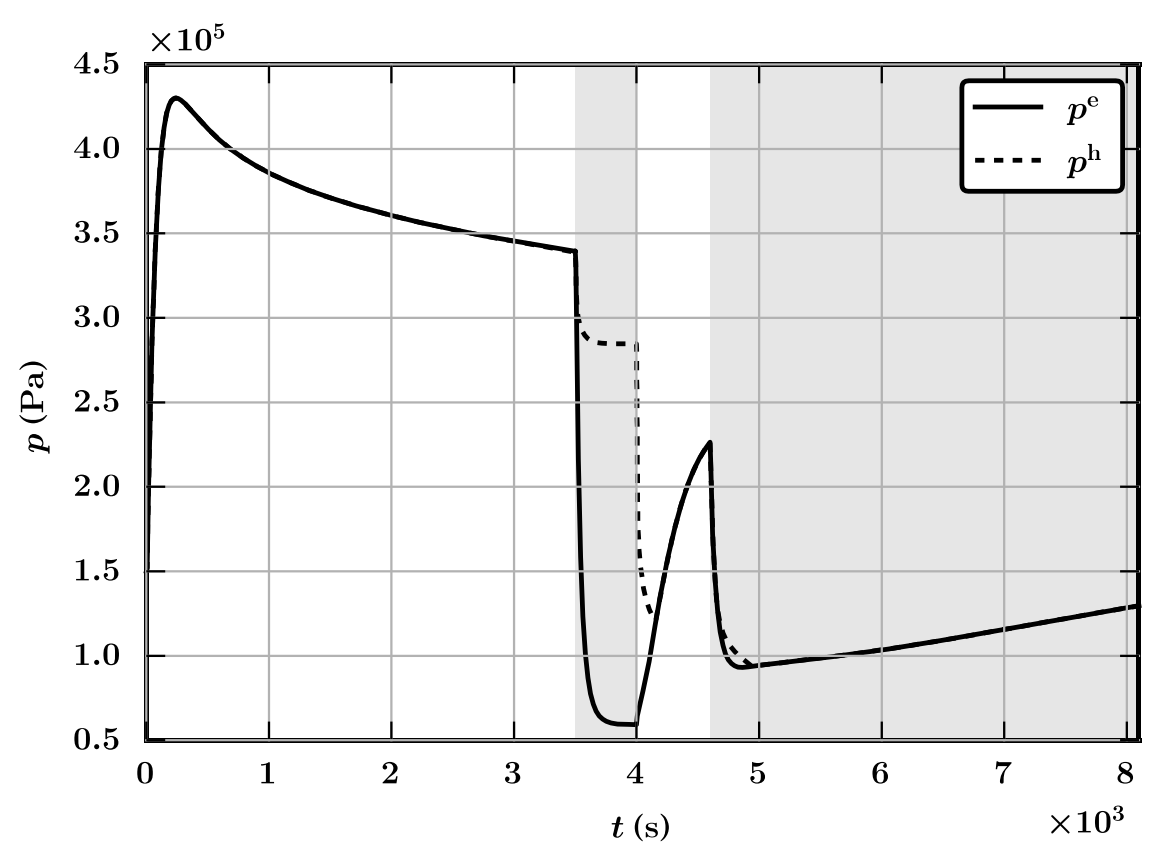

Figure 13. Variation in hydrogen pressure in the beds 


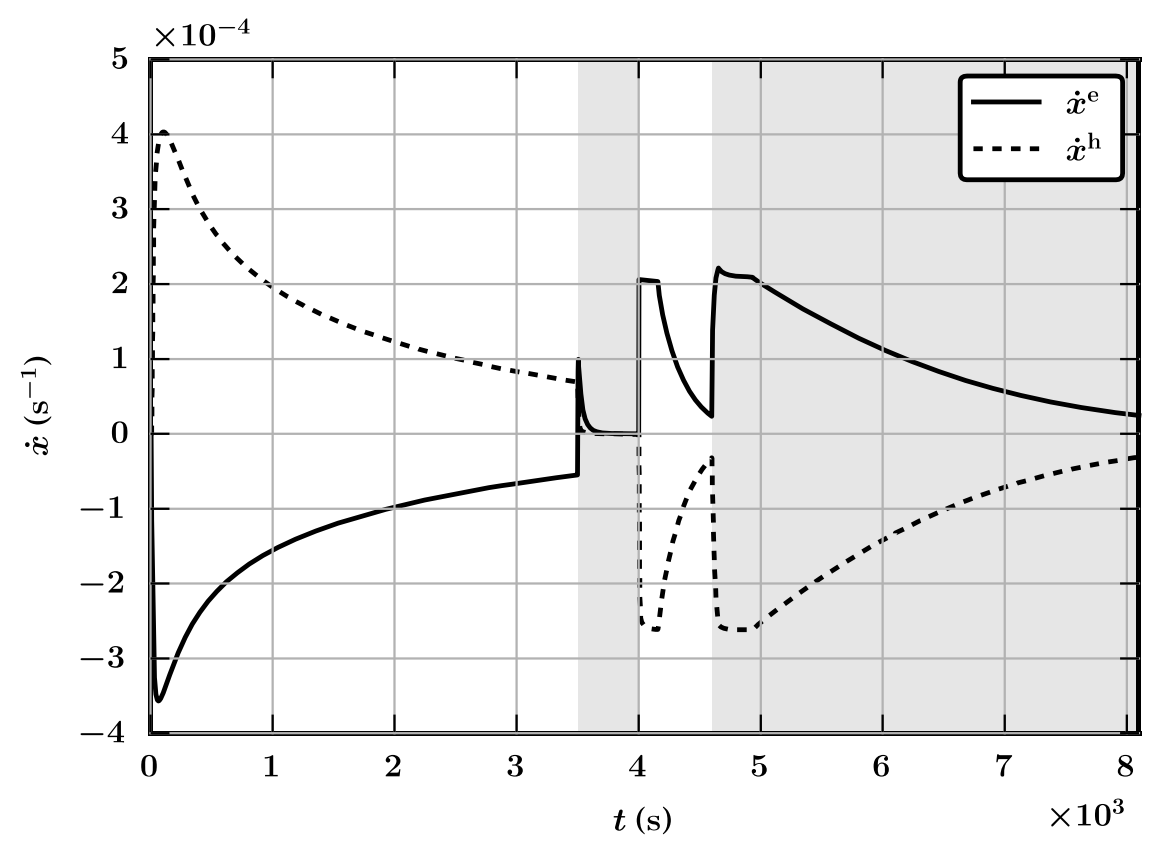

Figure 14. Variation in rate of reaction in the beds 


\section{LIST OF TABLES}

Table 1. Thermo-physical properties [17-20]

Table 2. Parameters of $p-x-T$ characteristics

Table 3. Parameters for reaction kinetics [23] 
Table 1. Thermo-physical properties [17-20]

\begin{tabular}{lcc}
\hline & $\mathbf{L a N i}_{\mathbf{4} .7} \mathbf{A l}_{\mathbf{0} .3}$ & $\mathbf{L a N i}_{\mathbf{5}}$ \\
\hline$\rho^{\mathrm{a}}\left(\mathrm{kgm}^{-3}\right)$ & 8330 & 7960 \\
\hline $\mathrm{o}$ & 0.68 & 0.69 \\
\hline$c^{\mathrm{a}}\left(\mathrm{Jkg}^{-1} \mathrm{~K}^{-1}\right)$ & 419 & 419 \\
\hline$w_{\mathrm{m}}^{\mathrm{r}}\left(\mathrm{kgkg}^{-1}\right)$ & 0.0143 & 0.0136 \\
\hline
\end{tabular}


Table 2. Parameters of $p-x-T$ characteristics

\begin{tabular}{lcc}
\hline & $\mathbf{L a N i}_{\mathbf{4} .7} \mathbf{A l}_{\mathbf{0 . 3}}$ & $\mathbf{L a N i}_{\mathbf{5}}$ \\
\hline$p^{!} \quad(\mathrm{Pa})$ & $1 \times 10^{5}$ & $1 \times 10^{5}$ \\
\hline$A$ & 12.92 & 13.44 \\
\hline$B(\mathrm{~K})$ & 4068 & 3780 \\
\hline$\phi$ & 0.3 & 0.038 \\
\hline$\tilde{\phi}$ & 0.005 & 0 \\
\hline$\beta$ & 0.098 & 0.137
\end{tabular}


Table 3. Parameters for reaction kinetics [23]

\begin{tabular}{ccc}
\hline & $\mathbf{L a N i}_{\mathbf{4} .7} \mathbf{A l}_{\mathbf{0 . 3}}$ & $\mathbf{L a N i}_{\mathbf{5}}$ \\
\hline$\sigma_{F}, \sigma_{D}\left(\mathrm{~s}^{-1}\right)$ & 594 & 86 \\
\hline$E_{F}, E_{D}\left(\mathrm{Jmol}^{-1}\right)$ & 29100 & 27700 \\
\hline
\end{tabular}

[24] 